\title{
A mutation in the human MPDU1 gene causes congenital disorder of glycosylation type If (CDG-If)
}

\author{
Christian Kranz, ${ }^{1}$ Jonas Denecke, ${ }^{1}$ Mark A. Lehrman, ${ }^{2}$ Sutapa Ray, ${ }^{3}$ Petra Kienz, ${ }^{1}$ \\ Gunilla Kreissel, ${ }^{1}$ Dijana Sagi, ${ }^{4}$ Jasna Peter-Katalinic, ${ }^{4}$ Hudson H. Freeze, ${ }^{5}$ \\ Thomas Schmid, Sabine Jackowski-Dohrmann, ${ }^{6}$ Erik Harms, ${ }^{1}$ \\ and Thorsten Marquardt ${ }^{1}$
}

${ }^{1}$ Klinik und Poliklinik für Kinderheilkunde, Münster, Germany

${ }^{2}$ Department of Pharmacology, University of Texas Southwestern Medical Center, Dallas, Texas, USA

${ }^{3}$ University of Texas Medical Branch, Galveston, Texas, USA

${ }^{4}$ Institut für Medizinische Physik und Biophysik, Münster, Germany

${ }^{5}$ The Burnham Institute, La Jolla, California, USA

${ }^{6}$ Zentrum für Kinderheilkunde, Philipps-Universität, Marburg, Germany

Address correspondence to: Thorsten Marquardt, Klinik und Poliklinik für Kinderheilkunde, Albert-Schweitzer-Strasse 33, 48129 Münster, Germany. Phone: 49-251-835-8519; Fax: 49-251-835-6085; E-mail marquat@uni-muenster.de.

Received for publication June 28, 2001, and accepted in revised form October 15, 2001.

\begin{abstract}
We describe a new congenital disorder of glycosylation, CDG-If. The patient has severe psychomotor retardation, seizures, failure to thrive, dry skin and scaling with erythroderma, and impaired vision. CDG-If is caused by a defect in the gene MPDU1, the human homologue of hamster Lec35, and is the first disorder to affect the use, rather than the biosynthesis, of donor substrates for lipid-linked oligosaccharides. This leads to the synthesis of incomplete and poorly transferred precursor oligosaccharides lacking both mannose and glucose residues. The patient has a homozygous point mutation $(221 \mathrm{~T} \rightarrow \mathrm{C}, \mathrm{L} 74 \mathrm{~S})$ in a semiconserved amino acid of MPDU1. Chinese hamster ovary Lec35 cells lack a functional Lec35 gene and synthesize truncated lipid-linked oligosaccharides similar to the patient's. They lack glucose and mannose residues donated by Glc- $P$-Dol and Man- $P$-Dol. Transfection with the normal human MPDU1 allele nearly completely restores normal glycosylation, whereas transfection with the patient's MPDU1 allele only weakly restores normal glycosylation. This work provides a new clinical picture for another CDG that may involve synthesis of multiple types of glycoconjugates.
\end{abstract}

J. Clin. Invest. 108:1613-1619 (2001). DOI:10.1172/JCI200113635.

\section{Introduction}

Congenital disorders of glycosylation (CDGs) are a rapidly growing group of inherited multisystem disorders in humans caused by defects in protein and lipid glycosylation. So far, five different genetic defects have been described that affect the biosynthesis of dolichylpyrophosphate-linked oligosaccharide (CDGIa to CDG-Ie) and three defects that alter the processing of N-linked glycans on proteins (CDG-IIa to CDG-IIc) (for review see ref. 1). In this paper we describe the identification of a new defect in the biosynthesis of dolichylpyrophosphate-linked oligosaccharides that results from defective mannosylation and glucosylation of glycans in the lumen of the rough endoplasmic reticulum (RER). This disorder, named CDG-If, is caused by a mutation in the MPDU1 gene that is essential for the bioavailability of dolichol- $P$ mannose and dolichol-P-glucose within the RER.

The Lec35 defect was first described in a mutant cell line of Chinese hamster ovary $(\mathrm{CHO})$ cells that was selected for resistance to concanavalin A in the presence of swainsonine. These cells accumulated the truncated dolichylpyrophosphate-linked oligosaccharide $\mathrm{Man}_{5} \mathrm{Glc}$ $\mathrm{NAc}_{2}$, which gives rise to asparagine-linked oligosaccharides lacking the two mannosyl residues removed by the swainsonine-sensitive enzyme Golgi mannosidase II (2). In addition to mannosylation, Lec35 cells are also defective in glucosylation (3) of dolichylpyrophosphate-linked oligosaccharides on the luminal side of the RER. Furthermore, they show a defective first mannosylation step of glycosylphosphatidylinositol (GPI) anchor biosynthesis (4) and a defective C-mannosylation of tryptophan (3). Thus, all known classes of monosaccharide-Pdolichol-dependent glycosyltransferase reactions in mammalian cells require the Lec35 gene. Lec35 mutants have a normal level of dolichol- $P$-mannose as well as normal activities of dolichol- $P$-mannose synthase and mannosyltransferase VI (5). Furthermore, biochemical experiments ruled out a general inhibitor of such reactions (3). Instead, the Lec 35 protein has been implicated in the precise presentation or "flipping" of dolichol- $P$-sugars in the ER membrane. This hypothesis is supported by the observation that the Lec35 defect is corrected by physical perturbation $(3,4)$. Although it is unlikely that Lec $35 p$ is 
the "flippase" itself (3), the protein may be necessary for the correct spatial localization of dolichol- $P$-sugars in the flipping process. The coding sequence of Lec 35 from the hamster (GenBank accession number U55387) (6), as well as its genomic organization (GenBank accession number AF250736) (3), have been published and predicts an ER-associated membrane protein of 247 amino acid residues. One particularly well-characterized isolate, Lec35.1, was shown to result from a deletion that eliminated at least two of seven coding exons (3). In humans, the homologous gene on chromosome 17p12-13 has been designated MPDU1 (mannose- $P$-dolichol utilization defect 1) (GenBank accession number AC007421) (3). No human disorders based on a defect of this gene have been described so far.

In this article we describe the discovery of a patient with a homozygous mutation in the MPDU1/Lec35 gene. Serum glycoproteins are hypoglycosylated, and the patient has a multisystem disorder with amaurosis and profound psychomotor retardation. Fibroblasts of the patient synthesize truncated lipid-linked oligosaccharides. Stable transfection of the human wild-type gene into Lec35 CHO cells restored nearly normal lipid-linked oligosaccharide (LLO) biosynthesis, whereas introduction of the patient's Lec35 coding sequence resulted in the same biosynthetic defect as seen in his fibroblasts.

\section{Methods}

Gel electrophoresis and MALDI-TOF. The combination of two-dimensional gel and electrophoresis and matrixassisted laser desorption/ionization time-of-flight (MALDI-TOF) has been developed for identification of $\mathrm{N}$-glycans in CDG (7). One- and two-dimensional electrophoresis was done as described (8). In-gel deglycosylation was performed as described earlier (9). Gel spots were excised from a gel, and proteins in the gel were reduced with $45 \mathrm{mM}$ DTT for 30 minutes at $60^{\circ} \mathrm{C}$ and alkylated with $100 \mathrm{mM}$ iodacetamide for $30 \mathrm{~min}$ utes in the dark at room temperature. Gel pieces were washed twice for 30 minutes in acetonitrile $/ 20 \mathrm{mM}$ $\mathrm{NaHCO}_{3}, \mathrm{pH} 7.2(1: 1 \mathrm{vol} / \mathrm{vol})$ and dried in a vacuum centrifuge. To the dried gel pieces the PNGase F solution in $20 \mathrm{mM} \mathrm{NaHCO} 3, \mathrm{pH} 7.2(100 \mathrm{U} / 500 \mu \mathrm{l})$, was added and incubated overnight at $37^{\circ} \mathrm{C}$. Glycans were extracted from the gel pieces by two exchanges of pure water and two exchanges with $50 \%$ acetonitrile, with sonication for 30 minutes each. Native $N$-glycans were purified by graphitized microcolumns (10). Sialylated $\mathrm{N}$-glycans were converted into methyl esters with methyliodide in dry DMSO and purified in a microcolumn consisting of AG $3\left(\mathrm{OH}^{-}\right.$form, bottom) and AG-50 ( $\mathrm{H}^{+}$form, top) (9).

Mass spectra were acquired on a TofSpec 2E mass spectrometer (Micromass UK Ltd., Manchester, United Kingdom) operated in the positive-ion mode using reflectron. Sugar samples were loaded onto the mass spectrometer target in $1 \mu \mathrm{l}$ water and mixed with $1 \mu \mathrm{l}$ of freshly made trihydroxyacetophenon $(20 \mathrm{mg} / \mathrm{ml}) /$ ammonium citrate
$(20 \mathrm{mM})$ in acetonitrile/water $(1: 1 \mathrm{vol} / \mathrm{vol})$. Neutral and sialylated glycans after esterification were observed as $[\mathrm{M}+\mathrm{Na}]^{+}$ion accompanied by a smaller signal of the respective $[\mathrm{M}+\mathrm{K}]^{+}$ion in the positive ion spectra.

$H P L C$ analysis of $L L O$ and protein-derived oligosaccharides. Cells were labeled for 30 minutes with $100 \mu \mathrm{Ci}\left[2-{ }^{3} \mathrm{H}\right]-$ mannose per milliliter of labeling medium (DMEM without glucose/MEM; 9:1), chased for 10 minutes in MEM, and washed with PBS. Plates were put on ice, and the cells were scraped in $3 \mathrm{ml}$ methanol and transferred to a glass tube. After addition of $6 \mathrm{ml}$ chloroform and vigorous mixing, the samples were spun, and the pellet was re-extracted twice with chloroform/methanol (2:1). The pellet was then dried under nitrogen and extracted several times with water. Dolichylpyrophosphate-linked oligosaccharides were predominantly recovered from the subsequent chloroform/methanol/water (10:10:3) extract and released by mild acid hydrolysis for $20 \mathrm{~min}$ utes at $100^{\circ} \mathrm{C}$ in $n$-propranolol/ $0.1 \mathrm{~N} \mathrm{HCl}(1: 2)$. The pellet after the chloroform/methanol/water extraction was digested overnight at $37^{\circ} \mathrm{C}$ with PNGase F after denaturation for 10 minutes at $100^{\circ} \mathrm{C}$ to release the proteinlinked oligosaccharides. HPLC was done in an acetonitrile/water gradient using a Microsorb MV column (Varian GmbH, Darmstadt, Germany) with a Waters Alliance system (Waters GmbH, Eschborn, Germany).

Mutation analysis. Human MPDU1 mRNA was transcribed by reverse transcriptase (first-strand cDNA synthesis kit; Roche Diagnostics, Mannheim, Germany), and the coding sequence was amplified by PCR. Primers were SL35-F-(13F) 5'-TGTAAAACGACGGCCAGTCTGGCGGAAGCTAGCTTTGC-3' (NheI restriction site underlined) and SL35-R-(13R) 5'-CAGGAAACAGCTATGACCCGGAATGACTCCAGTAGCTGGC- $3^{\prime}$, and the samples were incubated at $94^{\circ} \mathrm{C}$ for 3 minutes. Thirtyfive cycles with $94^{\circ} \mathrm{C}$ for 1 minute, $50^{\circ} \mathrm{C}$ for $45 \mathrm{sec}-$ onds, and $72^{\circ} \mathrm{C}$ for 1.5 minutes were followed by a final incubation at $72^{\circ} \mathrm{C}$ for 10 minutes. Q-Solution (QIAGEN Inc., Valencia, California, USA) was added for the incubations. Proofreading polymerase Pwo (Roche Diagnostics) was used for the generation of cDNA for expression cloning. Buffer conditions for PCR amplification were: $10 \mathrm{mM}$ Tris- $\mathrm{HCl}, \mathrm{pH} 8.85,25 \mathrm{mM} \mathrm{KCl}$, $5 \mathrm{mM}\left(\mathrm{NH}_{4}\right)_{2} \mathrm{SO}_{4}$, and $2 \mathrm{mM} \mathrm{MgSO}_{4}$.

For confirmation of the mutation at the genomic level, exon 3 was amplified using the primers Lec35IVS2-F-(13U) 5'-TGTAAAACGACGGCCAGTATTACCCTTGGGGTGGAAGG-3' and Lec35-IVS3-R-(13R) $5^{\prime}$ CAGGAAACAGCTATGACCGAGGCCATCAACTGTGTGGG$3^{\prime}$. After an incubation at $94^{\circ} \mathrm{C}$ for 3 minutes, the samples were cycled 35 times: $94^{\circ} \mathrm{C}$ for 1 minute, $60^{\circ} \mathrm{C}$ for 45 seconds, and $72^{\circ} \mathrm{C}$ for 1 minute. Final incubation was at $72^{\circ} \mathrm{C}$ for 10 minutes. Q-Solution was added for the incubations.

The mutation $221 \mathrm{~T} \rightarrow \mathrm{C}(74 \mathrm{Leu} \rightarrow \mathrm{Ser})$ of our patient generates a new TaqI (New England BioLabs Inc., Beverly, Massachusetts, USA) restriction site. Restriction analysis of exon 3 of 50 healthy donors of Caucasian European background was performed to exclude a common poly- 


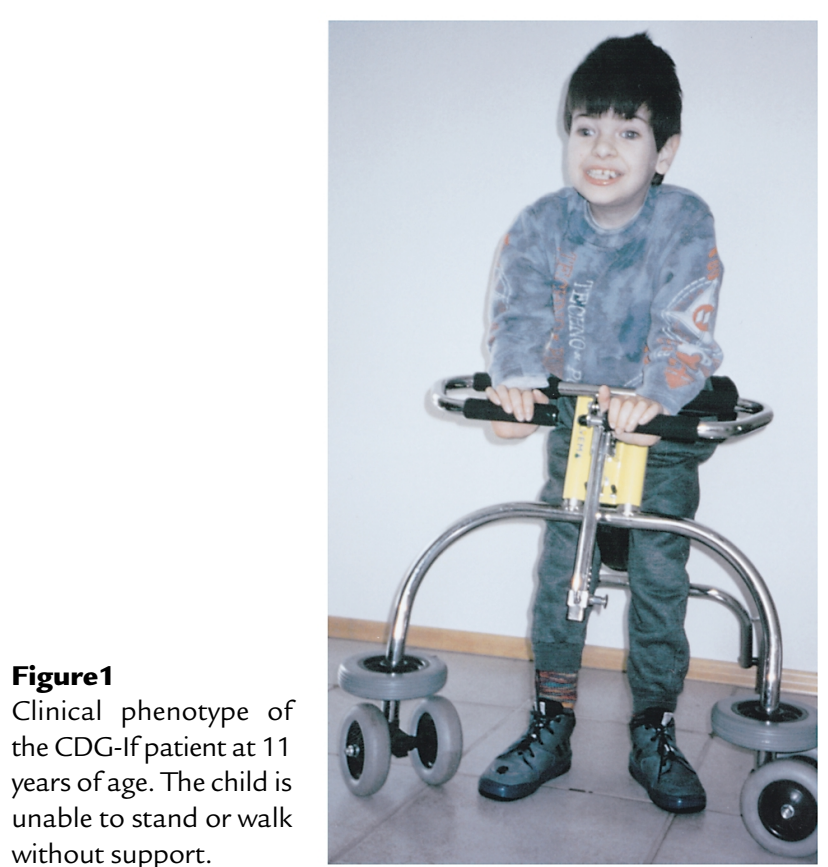

morphism in the human MPDU1 gene. Incubations were done at $65^{\circ} \mathrm{C}$ for 3 hours in $10 \mathrm{mM}$ Tris- $\mathrm{HCl}, \mathrm{pH} 8.4,100$ $\mathrm{mM} \mathrm{NaCl}, 10 \mathrm{mM} \mathrm{MgCl}_{2}$, and $100 \mu \mathrm{g} / \mathrm{ml} \mathrm{BSA}$.

In this investigation, the published sequences of human MPDU1 at the genomic level (accession number AC007421) and of the coding region (accession number XM_008236) have been used and confirmed.

Construction of the expression vector. The cDNA generated by the PCR reaction described above using SL35-F(13F) and SL35-R-(13R) was digested with NheI (New England BioLabs Inc.) and cloned into the expression vector pTre2hyg (CLONTECH Laboratories Inc., Palo Alto, California, USA) that had been digested with NheI and EcoRV (New England BioLabs Inc.). After amplification in bacteria (TOP10F'; Invitrogen Corp., San Diego, California, USA), the vector constructs were purified, and the sequence of the coding region was verified by direct sequencing using a LI-COR sequencer (LI-COR Biosciences, Bad Homburg, Germany).

Transfection of Lec35 CHO cells. Lec35.1 Tet-Off cells were obtained by transfection of Lec35.1 cells (3) with pTetOff (CLONTECH Laboratories Inc.) by the calcium phosphate procedure and selection in F-12 medium (Invitrogen Corp., San Diego, California, USA) containing $10 \%$ serum and $1 \mathrm{mg} / \mathrm{ml} \mathrm{G} 418$ (Invitrogen Corp.). A stably transfected colony was isolated with a cloning cylinder and propagated. The activity of the incorporated pTet-Off plasmid was confirmed by transiently transfecting pTRE-Luc (CLONTECH Laboratories Inc.) into a portion of the cells with Fugene 6 Transfection Reagent (Roche Diagnostics), incubating in F-12 medium plus $10 \%$ tetracycline-free serum (CLONTECH Laboratories Inc.) in the absence or presence of $50 \mathrm{ng} / \mathrm{ml}$ doxycycline (CLONTECH Laboratories Inc.), and monitoring luciferase expression (luciferase assay system;
Promega Corp., Madison, Wisconsin, USA) 48 hours after transfection. Luciferase expression was inhibited approximately 100 -fold by doxycycline. The Lec 35 glycosylation defect was retained as judged by resistance to concanavalin $\mathrm{A} /$ swainsonine selection (not shown) and synthesis of $\mathrm{Man}_{5} \mathrm{GlcNAc}_{2}-P$-P-dolichol (see Results).

For transfection with pTRE constructs, cells were grown to $80 \%$ confluence and transfected with $15 \mu \mathrm{g}$ of the vector construct using commercially available liposomes (Transfast; Promega Corp.) (DNA/liposome ratio $1: 1)$. Transient transfection occurred in $50-70 \%$ of the cells as judged by expression of constructs bearing the cDNA of green fluorescent protein (GFP). Lec35.1 Tetoff cells were transfected either with the vector pTre2hyg, or with pTre2hyg containing the human wild-type MPDU1 coding sequence (pTre2hyg control), or with pTre2hyg containing the mutated MPDU1 coding sequence of the patient (pTre2hyg patient). Cells were grown in $\alpha M E M$ containing $10 \%$ tetracycline-free FBS (CLONTECH Laboratories Inc.). Forty-eight hours later, hygromycin $\mathrm{B}$ was added to the culture medium to a final concentration of $400 \mu \mathrm{g} / \mathrm{ml}$. After another 48 hours, hygromycin concentration was reduced to 200 $\mu \mathrm{g} / \mathrm{ml}$, and the cells were grown in this medium for 8 days. Mortality rate of nontransfected cells was greater than $95 \%$ under these conditions. Ten days after the transfection, the stably transfected cells were labeled with $\left[2-{ }^{3} \mathrm{H}\right]$-mannose and LLOs were analyzed by HPLC. In addition, clones were isolated from the pool of stable transfectants using standard procedures.

\section{Results}

Clinical phenotype. The boy was born in June 1987 after an uneventful pregnancy of 39 weeks (weight 2,770 g, length $48 \mathrm{~cm}$, head circumference $36 \mathrm{~cm}$ ). The parents are not consanguineous, but both families have lived in the same village for generations. Muscular hypotonia and contractures were noted after birth, but otherwise the child appeared to be normal. Horizontal nystagmus and a lack of visual fixation was obvious at 3 months of age, and amaurosis was diagnosed 3 months later. Divergent strabismus was noted. The electroretinograph showed no signal, although the morphology of the retina appeared to be normal. Seizures began at 5 months of age and frequently occurred from then on. Statomotor retardation was already noted at that time. Electroencephalograms showed hypersynchronic activity. Hearing was investigated with brainstem evoked response audiometry and was found to be normal. Computed tomography and magnetic resonance imaging scans of the brain revealed general cerebral atrophy. The skin was dry, hyperkeratotic, and scaling with erythroderma was present at the cheeks, thorax, and lower legs. No fungi could be cultivated from the lesions. The skin is still very dry but hyperemia and hyperkeratosis have disappeared. Gastrointestinal problems included decreased food intake, abdominal pain, and frequent vomiting without diarrhea. They occurred intermittently, and were a major problem when the boy was 3-4 
a

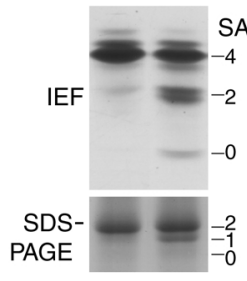

b

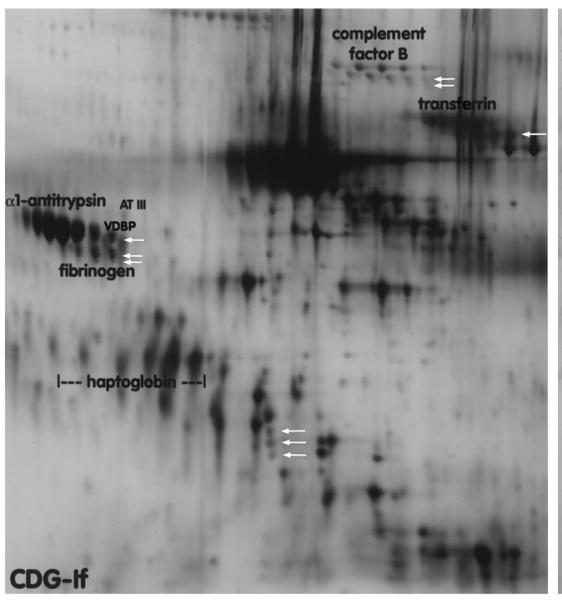

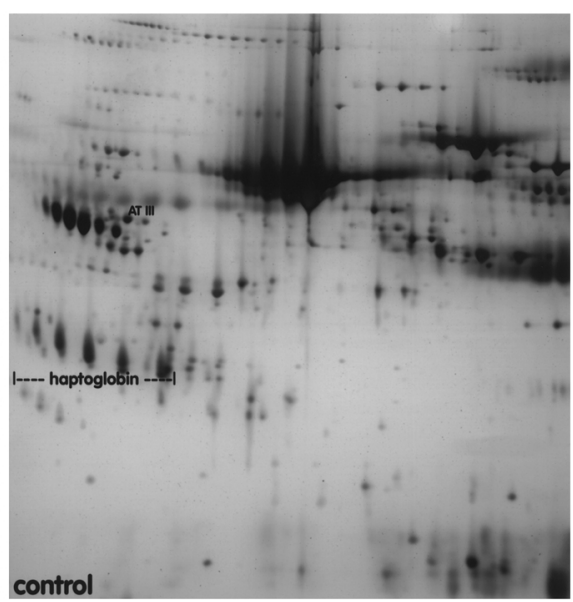

C

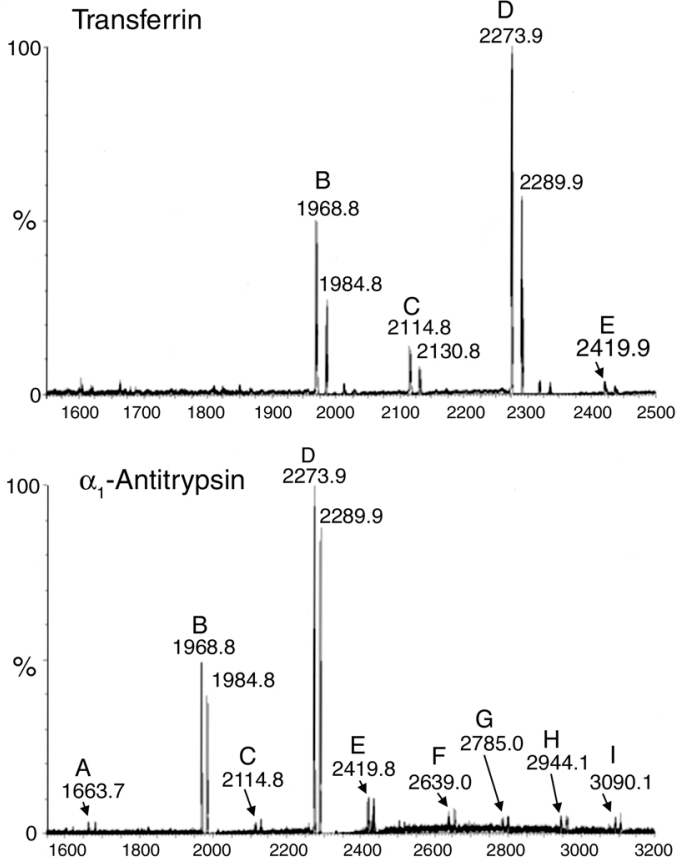

A

B

C
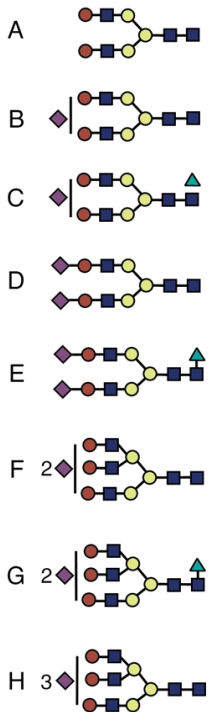

I $\left.3 \diamond\right|_{0-0} ^{0-a} 0$ 을

\section{Figure 2}

Electrophoresis of serum glycoproteins and MALDI-TOF of released oligosaccharides. (a) Upper panel: Transferrin IEF shows the occurrence of disialo- and asialotransferrin in the patient (SA, sialic acid). Lower panel: SDS PAGE of immunoprecipitated transferrin reveals the occurrence of two additional bands that are 2 or $4 \mathrm{kDa}$ smaller than the regular form (numbers designate the number of carbohydrate side chains). (b) Two-dimensional electrophoresis of serum proteins. Arrows, abnormal isoforms. (c) MALDI-TOF. Oligosaccharides were released from two-dimensional spots from transferrin and $\alpha 1$-antitrypsin and analyzed for their mass. Oligosaccharide patterns from the patient's proteins are shown. High-mannose oligosaccharides were absent. The patterns were identical to those found in controls (not shown). years of age. Gastroesophageal reflux was ruled out. A dystrophy with body weight, length, and head circumference below the third percentile developed. Ataxia and profound psychomotor retardation were noted at 5 years of age. At 7 years of age, he could sit without support, and at 10 years he could do so for up to 1 hour, but he was unable to stand or walk without support (Figure 1). At 2 years of age he could speak a few monosyllabic words, but this capability was lost again. At present, he is unable to speak but can communicate his moods by uttering distinct sounds. Regular reflexes are present at the lower extremities. Coagulation parameters, often decreased in CDG patients, showed a normal thrombin time and activated partial thrombin time, but a slightly reduced AT III activity of 50\%. Liver transaminases were not elevated.

Gel electrophoresis of serum proteins. Isoelectric focusing (IEF) of serum transferrin is the standard procedure for the diagnosis of CDG. Transferrin IEF of the child revealed the typical type I pattern with additional disia- lo- and asialo-bands as seen in CDG-Ia (Figure 2a, upper panel). SDS-PAGE of immunoprecipitated transferrin revealed the presence of two additional bands (Figure 2a, lower panel). These bands differ from each other in their apparent molecular weights by approximately 2 $\mathrm{kDa}$, suggesting the absence or severe truncation of one or both of the carbohydrate side chains. Transferrin IEF of both parents showed a normal pattern (not shown).

Two-dimensional electrophoresis of serum proteins demonstrated that the shifts in charge and apparent molecular weights were not restricted to transferrin but also occurred in a variety of different serum glycoproteins (Figure $2 b$ ). Transferrin and $\alpha 1$-antitrypsin spots were cut out from silver-stained two-dimensional gels, the carbohydrates were released by PNGase F in-gel digestion and subjected to MALDI-TOF analysis after methylation. The recovered carbohydrate chains were identical to the ones found in controls, suggesting that the carbohydrate side chains on serum glycoproteins were missing instead of being truncated (Figure 2c). 

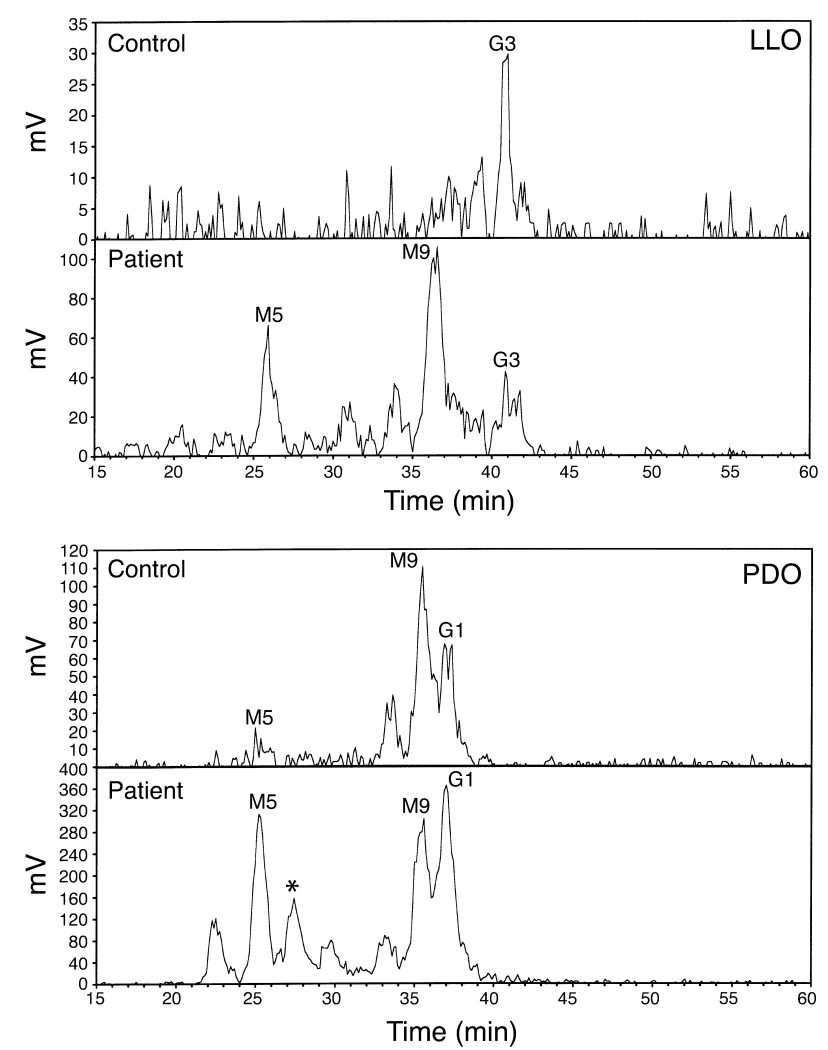

Figure 3

HPLC analysis of LLO (top panel) and PDO (bottom panel) from patient and control. The positions of $\mathrm{Man}_{5} \mathrm{GlcNAc}_{2}, \mathrm{Man}_{9} \mathrm{GlcNAc}_{2}$, $\mathrm{Glc}_{1} \mathrm{Man}_{9} \mathrm{GlcNAc}_{2}$, and $\mathrm{Glc}_{3} \mathrm{Man}_{9} \mathrm{GlcNAc}_{2}$ are indicated as M5, M9, G1, and G3. ${ }^{*} \mathrm{Glc}_{1} \mathrm{Man}_{5}$ or $\mathrm{Man}_{6}$.

Analysis of $L L O$ and protein-derived oligosaccharides. Primary fibroblasts were cultivated from a skin biopsy of the patient. Cells were incubated for 30 minutes with $\left[2-{ }^{3} \mathrm{H}\right]$-mannose to label newly synthesized oligosaccharides. A chase of 10 minutes was given so that the LLOs could reach full length. Oligosaccharides attached to dolichylpyrophosphate were then extracted by chloroform/methanol mixtures as described. Mild acid hydrolysis was used to release the oligosaccharides that were then fractionated by HPLC. Proteinbound oligosaccharides were released from the final pellet by PNGase F and analyzed by HPLC.

In control fibroblasts, the major oligosaccharide was found to be normal full-length $\mathrm{Glc}_{3} \mathrm{Man}_{9} \mathrm{GlcNAc}_{2}$ (abbreviated "G3" in Figure 3). In contrast, the patient's fibroblasts synthesized only a small amount of this oligosaccharide (Figure 3). Instead, the majority of the label was recovered as truncated oligosaccharides, namely $\mathrm{Man}_{9} \mathrm{GlcNAc}_{2}$ (Man9) and $\mathrm{Man}_{5}$ Glc$\mathrm{NAc}_{2}$ (Man5). The presence of these two major isoforms suggested a problem with the first Dol-PMan-dependent mannosylation step as well as with the first glucosylation step in the lumen of the RER. CDG-Ic was ruled out by sequencing of the glucosyltransferase gene, hALG6 (Genbank accession number NM_0133399) (not shown).

Protein-derived oligosaccharides (PDOs) were analyzed from the same experiments. PDOs were released by PNGase $\mathrm{F}$ from the final pellets after chloroform/methanol extractions. Due to cotranslational glucosidase action, the major oligosaccharides released from proteins of control cells are $\mathrm{G}_{1} \mathrm{Man}_{9} \mathrm{GlcNAc}_{2}$ and $\mathrm{Man}_{9} \mathrm{GlcNAc}_{2}$ (Figure 3). In the patient, these are also the most abundant oligosaccharides, but considerably more truncated forms are found migrating as expected for $\mathrm{Man}_{5-7} \mathrm{GlcNAc}_{2}$. It is possible that these truncated oligosaccharides could be glucosylated as seen in Lec35 CHO cells. Assuming similar kinetics of carbohydrate processing, this result is likely to be caused by an increased transfer of truncated oligosaccharides in the patient's cells, a phenomenon also described in CHO Lec 35 cells (2).

Since the affected LLO elongation steps are also defective in CHO Lec35 cells, the human homologue of Lec35 was further investigated.
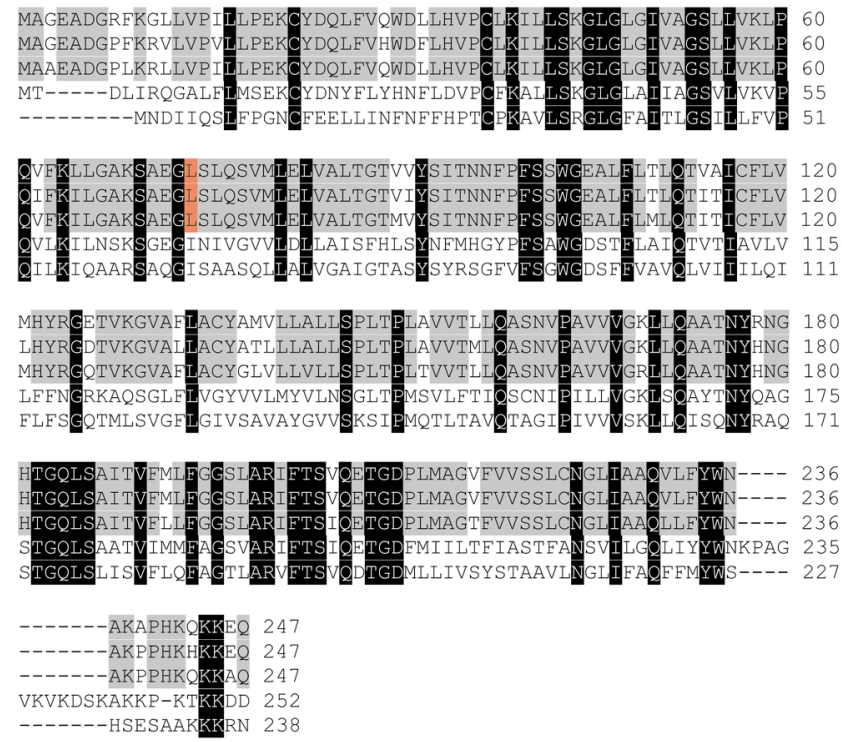

----HSESAAKKKRN 238

\section{Figure 4}

Multiple alignment of the protein sequences of Lec35 and homologues from different species. Regions that are conserved in all species are shown in black boxes. Grey boxes point out identical amino acids in the human, mouse, and hamster proteins. The red box identifies the mutated amino acid. F38E1.9 gene product (Caenorhabditis elegans, accession number AAA83473); CG3792 gene product (Drosophila melanogaster, AAF52190.2); Lec35 protein (Cricetulus griseus, AAG01096); Supl15h (Mus musculus, BAA78781.1), and mannose- $P$-dolichol utilisation defect 1 (Homo sapiens, XP_008236.1).

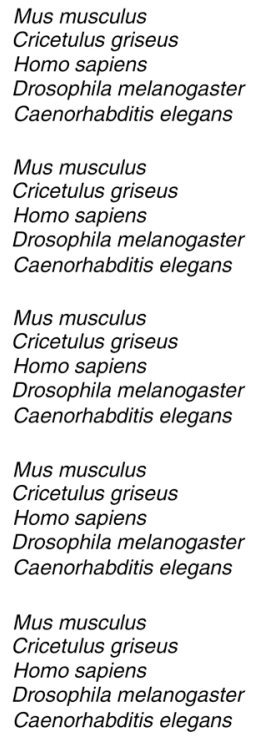




\section{Figure 5}

Taql restriction analysis of exon 3. The mutation $221 \mathrm{~T} \rightarrow \mathrm{C}$ generates a Taql restriction site. Both mutant alleles of the patient are cut with Taql $(P)$. One cut and one uncut allele shows the heterozygous state of the parents $(\mathrm{F}, \mathrm{M})$. Control DNA remains uncut $(C)$. $M$, marker; P, patient; F, father; $\mathrm{M}$, mother; $\mathrm{C}$, control.

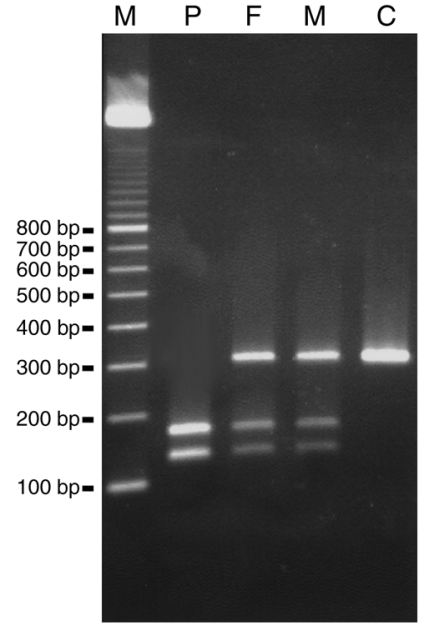

Sequencing of the buman MPDU1/Lec35 gene. The coding region of the human MPDU1 gene was sequenced from cDNA from the patient and control fibroblasts. The patient had a homozygous point mutation $221 \mathrm{~T} \rightarrow \mathrm{C}$ (74Leu $\rightarrow$ Ser), which was confirmed at the genomic level. Multiple alignment of the Lec 35 coding sequences from different species confirmed that aliphatic side chains are conserved at the position of the altered amino acid residue (Figure 4). The mutation generated a new TaqI restriction site. Restriction analysis of exon 3 showed the mutation in the patient as well as the heterozygous status of his parents (Figure 5). Fifty healthy European donors all had the normal sequence on both alleles, excluding this change as a common polymorphism in the human MPDU1 gene (not shown).

Expression of the human MPDU1/Lec35 in Lec35 CHO mutants. The cDNAs from controls and the patient were cloned into the pTre2hyg expression vector as described and expressed in Lec35.1 Tet-off cells in the absence of tetracycline. LLOs were labeled in stable transfectants for 30 minutes with $\left[2-{ }^{3} \mathrm{H}\right]$-mannose and chased for 10 minutes to allow completion of biosynthesis. The oligosaccharides were released from the extracted LLOs and analyzed by HPLC.

Lec35.1 Tet-off cells transfected with the vector bearing no insert showed the expected phenotype with a truncated oligosaccharide that was confirmed to be $\mathrm{Man}_{5} \mathrm{GlcNAc}_{2}$ by a fluorescent standard run in parallel (Figure 6a; vector). Parental wild-type $\mathrm{CHO}$ cells had the majority of the label in the full-length $\mathrm{Glc}_{3} \mathrm{Man}_{9} \mathrm{GlcNAc}_{2}$ oligosaccharide (Figure 6d; CHO parental). Lec35.1 $\mathrm{CHO}$ cells expressing the human homologue of their defective gene showed a considerable correction of the phenotype: $\mathrm{Man}_{5} \mathrm{GlcNAc}_{2}$ was nearly eliminated and $\mathrm{Glc}_{0-3} \mathrm{Man}_{9} \mathrm{GlcNAc}_{2}$ were the predominant oligosaccharides (Figure $6 \mathrm{~b}$; control cDNA). This nearly complete correction of mannosylation and partial correction of glucosylation was comparable to the correction that occurred when the hamster Lec35 cDNA was expressed in these cells. In contrast, when the patient's mutated cDNA was expressed, a similar LLO phenotype was observed as found in the patient's fibroblasts (Figure 6c; patient cDNA). The mRNA levels of the human MPDU1 message in both cell lines were analyzed by real-time PCR using actin as internal standard and were comparable in both cell lines (not shown).

\section{Discussion}

In this paper we describe a new disorder caused by a defect in the human MPDU1/Lec35 gene. According to the current nomenclature of congenital disorders of glycosylation, the new disease is called CDG-If. CDG-If is the first human glycosylation disorder affecting the use, rather than biosynthesis, of donor substrates for lipid-linked oligosaccharides.

The product of MPDU1/Lec35 is a small protein of $27 \mathrm{kDa}$ with two putative membrane-spanning regions and a cytosolic C-terminal ER retention signal (KKXX). The $\mathrm{N}$-terminal half of the protein is also predicted to have a cytosolic orientation (6). The protein is important for the efficient use of Dol- $P$-Man and Dol- $P$-Gluc, but not for their synthesis. A transfer of $\mathrm{Man}_{5} \mathrm{GlcNAc}_{2}$ to proteins has been shown in Lec35 CHO cells (2), demonstrating that the oligosaccharide itself has flipped to the luminal side of the RER.

In Lec35.1 CHO cells a large deletion in the gene leads to accumulation of $\mathrm{Man}_{5} \mathrm{GlcNAc}_{2}$, which is nearly the

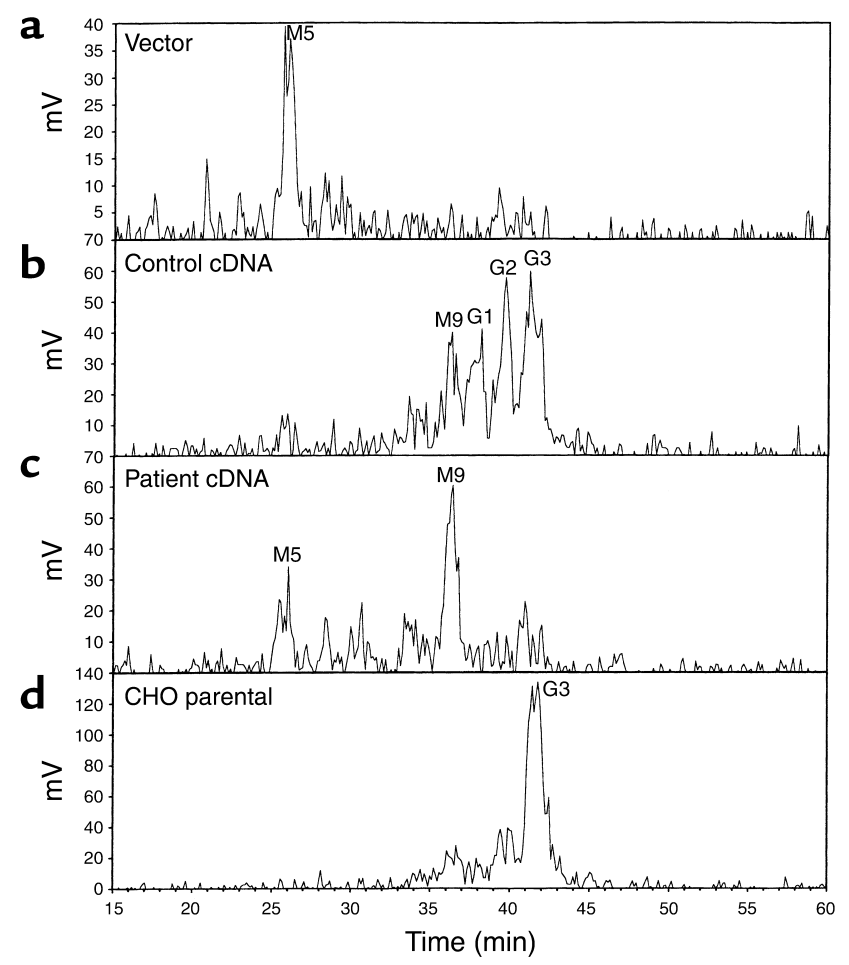

\section{Figure 6}

LLO profile of CHO MPDU1/Lec35 stable transfectants and controls. Lec35.1 pTet-Off cells were transfected with empty vector (a), the normal Lec35 allele (b), or the patient's MPDU1 allele (c). (d) Results with parental $\mathrm{CHO}$ wild-type cells. The positions of $\mathrm{Man}_{5} \mathrm{Glc}$ $\mathrm{NAc}_{2}$, Man9GlcNAc $2, \mathrm{Glc}_{1} \mathrm{Man}_{9} \mathrm{GlcNAc}_{2}, \mathrm{Glc}_{2} \mathrm{Man}_{9} \mathrm{GlcNAc}_{2}$, and $\mathrm{Glc}_{3} \mathrm{Man}_{9} \mathrm{GlcNAc}_{2}$ are indicated as M5, M9, G1, G2, and G3. 
only product synthesized. In contrast, the CDG-If patient accumulated $\mathrm{Man}_{5} \mathrm{GlcNAc}_{2}$ and $\mathrm{Man}_{9} \mathrm{GlcNAc}_{2}$, indicating that the missense mutation in the human homologue allows some oligosaccharides to be completely mannosylated.

Expression of the human MPDU1 gene in $\mathrm{CHO}$ Lec35 cells led to a substantial correction of the phenotype in transfected cells that synthesized $\mathrm{Glc}_{0-3} \mathrm{Man}_{9} \mathrm{GlcNAc}_{2}$ instead of $\mathrm{Man}_{5} \mathrm{GlcNAc}_{2}$. In contrast, transfection of the patient's mutated cDNA resulted in a partial correction of mannosylation, whereas glucosylation was still severely reduced. Thus, the LLO pattern of Lec35 cells transfected with the mutated human cDNA was nearly identical to the LLO pattern of the patient's fibroblasts, indicating that the described molecular alteration is actually causing the hypoglycosylation in this patient.

It is not surprising that CDG-If has a very severe phenotype because it is likely from the $\mathrm{CHO}$ studies that not only $\mathrm{N}$-glycosylation but also GPI anchor biosynthesis and C-mannosylation will be affected. In addition, disturbed folding of newly synthesized glycoproteins has been described in another Lec35-deficient CHO mutant, MadIA214, presumably caused by a defective interaction with ER chaperones $(3,11)$.

It is interesting to speculate whether any therapy might be devised from the insights into the cell biology of Lec35 cells. It has been shown that elevated amounts of GDP-mannose could correct defective mannosylation of the dolichylpyrophosphate-linked oligosaccharide in Lec35 membrane preparations (4). However, even if the cytoplasmic GDP-mannose pool could be increased in CDG-If patients, this might not be advisable because the affinity of OST toward partially elongated oligosaccharides could be even less than toward $\mathrm{Man}_{5} \mathrm{GlcNAc}_{2}$ (compare also Figure 3). Without restoration of the glucosylation, this might even be harmful.

CDG-If is a new disorder in the rapidly growing field of inherited glycosylation disorders. Not only has the understanding of these diseases led to the development of specific treatments for some of them $(8,12,13)$, but it is likely that new types of CDG will provide deeper insights into the biological consequences of abnormal or missing carbohydrates and that this will have an impact far beyond the small group of children with these inherited disorders.

\section{Acknowledgments}

This work was supported by grants from Deutsche Forschungsgemeinschaft (Ma 1229/3) and Innovative Medizinische Forschung (IMF) (MA 2298 24) to T. Marquardt; IMF grant (DE 110030) to J. Denecke; National Institutes of Health grants (DK55615) to H.H. Freeze and (GM38545) to M.A. Lehrman; and Welch Foundation grant (I-1168) to M.A. Lehrman. V. Sablitzky and K. Wardecki are acknowledged for technical assistance with the cell culture, S. Bushuven for help with the labeling experiments, C. Schottstädt and K. Lesiewicz for help with the preparation of MALDITOF samples, and D. Kemming for help with sequencing and immunofluorescence experiments. M. Aebi and $\mathrm{T}$. Hennet recently presented some data of their CDG-If patients in public and are acknowledged for sharing their insights ahead of publication.

1. Marquardt, T., and Freeze, H.H. 2001. Congenital disorders of glycosylation. Glycosylation defects in man and biological models for their study. Biol. Chem. 382:161-177.

2. Lehrman, M.A., and Zeng, Y. 1989. Pleiotropic resistance to glycoprotein processing inhibitors on Chinese hamster ovary cells. J. Biol. Chem. 264:1584-1593.

3. Anand, M., et al. 2001. Requirement of the Lec35 gene for all known classes of monosaccharide-P-dolichol-dependent glycosyltransferase reactions in mammals. Mol. Biol. Cell. 12:487-501.

4. Camp, L.A., Chauhan, P., Farrar, J.D., and Lehrman, M.A. 1993. Defective mannosylation of glycosylphosphatidylinositol in Lec35 Chinese hamster ovary cells. J. Biol. Chem. 268:6721-6728.

5. Zeng, Y.C., and Lehrman, M.A. 1990. A block at Man5GlcNAc2-pyrophosphoryldolichol in intact but not disrupted castanospermine and swainsonine-resistant Chinese hamster ovary cells. J. Biol. Chem. 265:2296-2305.

6. Ware, F.E., and Lehrman, M.A. 1996. Expression cloning of a novel suppressor of the Lec15 and Lec35 glycosylation mutations of Chinese hamster ovary cells. J. Biol. Chem. 271:13935-13938.

7. Sagi, D., Schottstädt, C., Lesiewicz, K., Marquardt, T., and Peter-Katalinic, J. 2001. Glycomics of aberrant N-glycosylation in CDG syndrome by in-gel deglycosylation and MALDI-TOF MS mapping. Glycoconj. J. 18:96. (Abstr.)

8. Niehues, R., et al. 1998. Carbohydrate-deficient glycoprotein syndrome type Ib. Phosphomannose isomerase deficiency and mannose therapy. $J$. Clin. Invest. 101:1414-1420.

9. Küster, B., Wheeler, S.F., Hunter, A.P., Dwek, R.A., and Harvey, D.J. 1997. Sequencing of $\mathrm{N}$-linked oligosaccharides directly from protein gels: ingel deglycosylation followed by matrix-assisted laser desorption/ionization mass spectrometry and normal-phase high-performance liquid chromatography. Anal. Biochem. 250:82-101.

10. Packer, N.H., Lawson, M.A., Jardine, D.R., and Redmond, J.W. 1998. A general approach to desalting oligosaccharides released from glycoproteins. Glycoconj. J. 15:737-747.

11. Ermonval, M., et al. 2000. Truncated $\mathrm{N}$-glycans affect protein folding in the ER of CHO-derived mutant cell lines without preventing calnexin binding. Glycobiology. 10:77-87.

12. Marquardt, T., et al. 1999. Correction of leukocyte adhesion deficiency type II with oral fucose. Blood. 94:3976-3985.

13. Lühn, K., Marquardt, T., Harms, E., and Vestweber, D. 2001. Discontinuation of fucose therapy in LAD II causes rapid loss of selectin ligands and rise of leukocyte counts. Blood. 97:330-332. 